Todos yacieron olvidados por la nueva voz, por el subterráneo ulular del nuevo signo que surgia como una montaña de sombras rugientes sobre un reducido espejo de silencio, que venía orillando los límites de la noche, desbordando los muros del espanto.

José Miguel Vicuña

ERES DE TIEMPO Y ERES DE LLAMA

Para Eliana Navarro

I

Eres de tiempo y eres de llama.

Cuando te mueres, ya no te mueres, y cuando llamas, ya no me llamas.

$\mathrm{Y}$ cuando aterras $\mathrm{y}$ desentierras las alegrias y las derramas, eres de cántaro, eres de rueca, eres de tímpano y de campana.

Cuando destinas, cuando resbalas, como de muerte, como de cántico. Y cuando lloras y te destruyes, y cuando penas y te desangras, cuando padeces, -desmemoriada. áspera, ruda-, cuando padeces, eres de sueño, de sombra y sangre. Si te tocara, si te vencicra, si te infundiera de mis entrañas; ipero eres roca, témpano estático!

\title{
I I
}

Te desafío, piedra, muralla, toco tus luces y me desgarras. 
Quiero tus torres, pero son alas;

tus capiteles, pero son lápida.

Caigo y te grito, mas no te alcanzo,

y retrocedo para escalarte.

Mudo vestigio de eternidades

inaccesible, te me abalanzo.

La muerte llevo para ablandarte,

ramas henchidas y ríos rápidos.

Como las olas, vuelvo al embate, y me despeñas y te agigantas.

\section{I I}

Eres de muerte cuando padeces, cuando progresas, cuando resbalas.

Cuando te mueres, ya no te mueres, y cuando llamas, ya no me llamas. ¿Cómo tenerte de sementeras, de atardeceres, de marejadas? Eres de cántaro; eres de rueca, eres de sueño, eres de rama. $\mathbf{Y}$ cuando creces, cuando padeces, cuando concibes o desentrañas, eres de muerte, eres de llama, cuando padeces y te desangras. 